\title{
Fatores determinantes no processo de decisão de investimentos em robotização na indústria brasileira de autopeças
}

\author{
Main factors on robotics investments decision \\ in the brazilian autoparts industry
}

\author{
Rene Meira Medina ${ }^{1}$ \\ Sérgio Feliciano Crispim ${ }^{1}$
}

\begin{abstract}
Resumo: A desverticalização do processo produtivo na indústria automobilística implicou na migração de parte da produção de sistemas e subsistemas dos veículos para a indústria de autopeças. Essa migração trouxe inovações no desenvolvimento de produtos e processos e novos padrões de qualidade. Dentre as inovações de processo destaca-se a robotização industrial, que conquista espaço crescente nas linhas de produção sob o argumento corrente relacionado aos ganhos de qualidade, além de vantagens ergonômicas, mas que demanda investimentos relativamente altos. Sendo esse um setor com baixa atratividade sob a ótica da rentabilidade e do retorno do capital, as decisões de investimentos em robotização revestem-se de importância relativamente elevada porque, além de impactarem significativamente os resultados financeiros, são decisões de natureza estratégica que influenciam a competitividade das empresas. Dado este contexto, esta pesquisa foi realizada com o objetivo de analisar quais são os fatores mais importantes no processo de decisão de investimento em robotização industrial nas empresas de autopeças brasileiras. Com base em entrevistas com especialistas dos fabricantes de robôs e de autopeças e em uma análise fatorial exploratória realizada com empresas de autopeças, concluiu-se que os aspectos financeiros relacionados a custos e retorno a longo prazo são os fatores de maior importância. Aspectos como tecnologia, qualidade e produtividade associadas à robotização têm uma importância secundária e, neste sentido e em relação a esta decisão, a estratégia de manufatura nas empresas de autopeças amostradas pode ser considerada subordinada à estratégia financeira, devendo a ela estar alinhada.
\end{abstract}

Palavras-chave: Robótica. Estratégia de manufatura. Decisão de investimentos. Autopeças.

\begin{abstract}
The deverticalization of the production process in the automotive industry has resulted in a migration of part of the production of vehicles systems and subsystems to the autoparts industry. Such migration has brought not only new quality standards, but also innovations in the development of products and processes and the increase in the effectiveness and competition to the supply chain. Amongst the innovations in process, there is the industrial robotization, which has conquered increasingly more space in the production lines due to its benefits regarding quality and ergonomic aspects. The decisions related to robotization are of strategic importance and demand high investments, and thus they are taken only by the top management of the autoparts companies. This industry presents low profitability and attractiveness under the return of investment point of view, which means that those companies have great responsibility for their results which, in turn, are directly influenced by the degree of competitiveness derived from the adopted strategic options. This study aims at analyzing the methods adopted in Brazilian autoparts companies by the people those responsible for investments in robotization and the correlation with manufacturing and financial strategies. A quantitative exploratory research was carried out on a nonprobabilistic sample of autoparts companies indicating that the costs of investments are more important during the investment decision, and that the manufacturing strategy depends upon the financial strategy.
\end{abstract}

Keywords: Robotics. Manufacturing strategy. Investments decision. Autoparts.

\section{Introdução}

A desverticalização do processo produtivo de autoveículos, no âmbito mundial, estimulou o desenvolvimento da indústria de autopeças, que hoje é autônoma, segmentada e orientada para a indústria automobilística. Paralelamente, a consolidação do modelo de estratégia de manufatura priorizou fatores como redução de custos, melhoria da qualidade, redução e confiabilidade dos prazos de entrega e

\footnotetext{
${ }^{1}$ Programa de Mestrado em Administração, Universidade Municipal de São Caetano do Sul - USCS, Campus II, Rua Santo Antônio, 50, CEP 09521-160, São Caetano do Sul - SP, Brasil, E-mails: rene.medina@ gmail.com; scrispim@uol.com.br
} 
flexibilidade produtiva (SKINNER, 1969; HAYES; WHEELWRIGHT, 1984; HILL, 2000). O processo de desverticalização caracteriza-se pela realocação de atividades ao longo da cadeia de suprimentos do setor automobilístico, que tem implicado em crescente transferência de tarefas das montadoras para os fabricantes de autopeças que tornam-se gradualmente montadores de sistemas automotivos. Este movimento tem criado a necessidade de uma maior e melhor interação entre os atores da cadeia logística, além de mudanças nos aspectos tecnológicos da indústria de autopeças (DI SERIO; SAMPAIO; PEREIRA, 2006).

No processo de redefinição da cadeia de suprimento da indústria automobilística e de busca de maior competitividade das empresas, a robotização industrial de várias atividades produtivas assume importância crescente na estratégia de manufatura. No Brasil, a robotização industrial foi implementada inicialmente pelas empresas montadoras de automóveis, que trouxeram essa tecnologia de suas matrizes para plantas antigas e novas, criando um cenário de modernidade no setor principalmente a partir do final da década de 90. Paralelamente, foram implantados no Brasil os escritórios comerciais das empresas fabricantes de robôs industriais, tendo como responsabilidade a pós-venda de seus produtos. Gradualmente a robotização avançou para a indústria de autopeças, e outros setores.

$\mathrm{O}$ investimento em robotização industrial nas empresas de autopeças do Brasil tem crescido nos últimos anos e, por representar valores relativamente elevados e ter importância estratégica, geralmente é decidido nos níveis hierárquicos mais altos. A formulação e implementação da estratégia de manufatura relacionada à robotização, que subordina-se à mais abrangente estratégia de negócio, é complexa e desafiadora devido a esse elevado investimento, que implica em análises técnicas e financeiras rigorosas e que precisa ser decidido à luz de fortes pressões das empresas montadoras que têm interesse na robotização de seus fornecedores. Esta situação alinha-se à argumentação de que as métricas convencionais de avaliação de investimento em geral não são mais apropriadas para as decisões de natureza estratégica (KAYALI, 2006).

Parte da lucratividade de uma empresa reflete diretamente a atratividade relacionada a fatores estruturais do setor em que está inserida, segundo Hitt, Ireland e Koskisson (2005), e no caso da indústria de autopeças e montadoras também, a atratividade é baixa sob a ótica da rentabilidade e do retorno sobre o investimento: em uma média de 5 anos terminados em 2008, o lucro líquido do setor automobilístico global foi de $3,4 \%$ e o retorno sobre o capital investido foi de 4,8\%, enquanto, na média das 500 empresas que compõem o índice S\&P-Standard \& Poors, estes coeficientes foram, respectivamente, de $11,8 \%$ e $12,4 \%$ (MSN, 2009). Mas, é importante destacar que além da atratividade setorial, de natureza externa, o resultado das empresas é influenciado por suas estratégia e ações, que definem sua competitividade face aos concorrentes, e que possibilita a obtenção de retornos superiores à média da indústria. Neste sentido, a robotização assume importância estratégica à medida que pode influenciar a competitividade das empresas de autopeças.

Dado este contexto, esse artigo tem por objetivo identificar os fatores determinantes no processo de decisão de investimentos em robotização na indústria de autopeças brasileira. Adicionalmente, busca contribuir para a compreensão da inserção da robotização nas estratégias de manufatura e suas relações com a competitividade.

\section{Competitividade e estratégia na manufatura}

A manufatura afeta a estratégia corporativa e a estratégia corporativa afeta a manufatura. A estratégia de manufatura deve alinhar-se à estratégia corporativa de forma a agregar competitividade ao negócio de forma geral. Neste sentido, uma operação eficiente, de baixo custo e com qualidade por si só não gera valor se não houver mercado para seus produtos e serviços (SKINNER, 1969; WHEELWRIGHT, 1984; CAGLIANO; CANIATO; SPINA, 2006).

Segundo Porter (1996), estratégia é a busca de uma posição exclusiva e valiosa, envolvendo diferentes conjuntos de atividades e pode ser definida em três níveis que correspondem a uma sequência hierárquica: estratégia corporativa, de negócio e funcional. A estratégia corporativa relaciona-se a duas importantes definições: os negócios em que a empresa irá competir e a forma de captação e alocação dos recursos entre estes negócios (WHEELWRIGHT, 1984). No nível de cada unidade corporativa, são definidas as estratégias de negócio, que podem ser formuladas de forma independente no sentido de buscar competitividade estratégica e retornos acima da média em cada mercado (HITT; IRELAND; KOSKISSON, 2005).

Dois componentes fundamentais da estratégia no nível de negócio, segundo Treacy e Wiersema (1999), são a proposição básica de valor a ser oferecido aos clientes e o modelo operacional que viabiliza esta proposição. Os valores propostos podem ser reduzidos a três estratégias alternativas: solução de menor custo para os clientes, produtos diferenciados e com qualidade superior, ou "intimidade com o cliente". Os modelos operacionais a estas proposições alinhados devem reforçar as disciplinas interna de valor: excelência operacional, liderança de produto e intimidade com os clientes. As disciplinas de valor, excelência operacional e liderança de produto, 
propostas por Treacy e Wiersema (1999), podem ser equiparadas às estratégias genéricas propostas por Porter (2004), nas quais os temas centrais são liderança de custo ou diferenciação, independente do enfoque de mercado escolhido. Porém, a disciplina de valor "intimidade com o cliente" corresponde a um novo tipo de estratégia de negócios em que a customização total, serviço superior e relacionamento com o cliente definem a vantagem competitiva.

Subordinada a cada estratégia de negócio, temos as estratégias funcionais. As estratégias funcionais devem ser desenvolvidas e operacionalizadas no sentido de dar suporte às estratégias de negócios e classicamente são: finanças, pesquisa e desenvolvimento, marketing, recursos humanos e manufatura. Dependendo do tipo de negócio, outras estratégias funcionais também podem ser definidas, como: serviços pós-venda, qualidade assegurada e logística. A estratégia funcional especifica como a função irá suportar a vantagem competitiva definida na estratégia de negócio e como será integrada às outras estratégias funcionais (WHEELWRIGHT, 1984; HILL, 2000).

É no nível funcional que se enquadra a estratégia de manufatura. Segundo Skinner (1969), um dos pioneiros neste tema, manufatura é parte de um conceito estratégico que relaciona as forças e os recursos da empresa ao mercado. Estratégia de manufatura é uma arma no arsenal competitivo de uma empresa. As decisões sobre os recursos da empresa refletem os trade-offs a elas associados, em que, ao ganhar de um lado, perde-se de outro, e, neste sentido, o ganho de qualidade normalmente correlaciona-se à perda de competitividade em custos. Para Wheelwright (1984), estratégia de manufatura consiste em uma sequência de decisões que habilitam a empresa a alcançar a vantagem competitiva desejada, e essas decisões podem ser organizadas em oito categorias: capacidades; utilidades; tecnologia; verticalização de processos; qualificação da mão de obra; qualidade; planejamento da produção e controle de materiais; e organização.

A estratégia de manufatura é o alicerce do sucesso estratégico e o motor competitivo da empresa e deve ser apropriada, abrangente, coerente, consistente no tempo e acreditável (SLACK; LEWIS, 2008). O desenvolvimento de uma estratégia de manufatura alinhada à estratégia de negócio, e consistente com toda a estrutura de decisões corporativas, pode, segundo Hill (2000), ser dividida em 5 passos: definição dos objetivos corporativos; determinação das estratégias de marketing para atingir os objetivos; julgamento dos produtos mais qualificados para os mercados face à concorrência; desenvolvimento do processo apropriado para a manufatura desses produtos; e provimento de da infraestrutura para suportar a produção.

A estratégia de manufatura abrange também os conceitos cedidos principalmente pelas empresas japonesas a partir da década de 80, como just-intime, total quality management, melhoria contínua, controle estatístico de processo, engenharia simultânea e produção enxuta (SCHONBERGER, 1986; CLARK, 1996). Esse novo paradigma, chamando de world class manufacturing, ou manufatura de classe mundial, é baseado na análise das práticas implementadas por empresas japonesas, americanas e alemãs que apresentavam rendimento notável em suas indústrias (HAYES; WHEELWRIGHT, 1984; SCHONBERGER, 1986; HAYES; PISANO, 1996). A inovação nos meios produtivos tem se tornado a base para o alcance desse novo paradigma, gerando maior competitividade estratégica em mercados globais (PRAJOGO et al., 2007). Voss (1995) afirma que as best practices (melhores práticas) baseiam-se no conceito de manufatura de classe mundial mas também abrangem outras áreas da empresa que contribuem para o aumento da competitividade. Os vários padrões de estratégia de manufatura possuem vantagens e desvantagens, e o desejável seria a utilização integrada de diferentes padrões, sendo importante que os resultados da estratégia de manufatura sejam monitorados por índices de desempenho visando uma realimentação e a melhoria contínua (VOSS, 1995).

A dinâmica dos novos produtos, bem como a diminuição do seu ciclo de vida, faz com que os Sistemas de Manufatura Flexível (FMS - Flexible Manufacturing System) sejam desenhados para tal propósito, possibilitando que a troca de produtos (setups) se torne automática e independente do volume a ser produzido. Com isso, há uma otimização dos recursos investidos, porém, apenas em famílias de produtos (HILL, 2000). A vantagem competitiva para a manufatura pode ser delineada pelas dimensões custo, qualidade, confiabilidade, flexibilidade e inovação. Estas dimensões devem ser aplicadas a linhas de produtos e tecnologias de produção em função do ambiente competitivo. No intuito de ser competitivo no mercado, a melhoria contínua dessas dimensões deve ser perseguida visando superar os concorrentes. Com as dimensões delineadas, o próximo passo é a definição dos padrões de decisão com base na posição e no grau da competição do mercado (WHEELWRIGHT; BOWEN, 1996). Além da melhoria contínua e integração dos processos internos, o aumento da competitividade fundamenta-se cada vez mais na integração e no alinhamento de processos entre as empresas de uma cadeia de valor (CAGLIANO; CANIATO; SPINA, 2006).

\section{Decisão de investimento em robotização}

Mais do que qualquer outro elemento da manufatura, a tecnologia do processo define a natureza da operação (SLACK; LEWIS, 2008). Muitas decisões no nível dos 
negócios para produção são exclusivamente baseadas em tecnologia, e a consequência disso é que acabam sendo tomadas pelos engenheiros e especialistas de processo, que são os conhecedores de tecnologia. Essa perspectiva pode criar situações para a manufatura e os negócios nas quais o enfoque adotado por cada um isoladamente dificulta o desenvolvimento de uma estratégia integrada geral (SKINNER, 1969; HILL, 2000).

Skinner (1969) e Hill (2000) explicitam que manufatura não é uma função relacionada à tecnologia diretamente, mas sim uma função relacionada aos negócios. A escolha apropriada para a manufatura de um produto deve levar em conta o que será fabricado internamente e o quanto será terceirizado, a identificação das alternativas tecnológicas apropriadas para cada etapa de manufatura do produto e a escolha do melhor processo tecnológico, considerando todas as etapas e áreas envolvidas dentro da companhia.

Para o processo tecnológico, Slack e Lewis (2008) inferem que mesmo nos mais dominantes tipos de tecnologia sempre há um grau de escolha. Deve-se analisar três dimensões: (i) tamanho; (ii) grau de automação; e (iii) grau de integração. A automação em qualquer tipo de processo pode economizar em mão de obra e reduz a variabilidade no sistema de manufatura. Normalmente justifica-se a automação com base na economia de mão de obra, mas, a invariabilidade do processo automatizado traz ganhos mais significativos. A escolha tecnológica também deve ser adequada ao perfil do produto. Investimentos em robotização industrial têm sido justificados com base em sua eficácia e em sua eficiência, mas, além do retorno sobre investimento e valor presente do fluxo de caixa descontado, fatores como flexibilidade de volume, qualidade e confiabilidade também devem ser avaliados na decisão de processo (SLACK; LEWIS, 2008).

Segundo a International Federation of Robotics (2007), de todos os robôs instalados no mundo, $70 \%$ são robôs articulados instalados em indústrias manufatureiras, existem seis classificações para os robôs industriais conforme a estrutura mecânica, sendo elas: robô cartesiano, robô cilíndrico, robô esférico, robô Scada, robô articulado e robô paralelo. Os robôs articulados industriais são utilizados em diferentes tipos de aplicações. Entre as aplicações mais utilizadas e sua participação relativa, conforme International Federation of Robotics (2007) e dados da United Nations Economic Commission for Europe, estão a solda ponto (26\%), solda arco (24\%), manipulação (37\%), paletização $(6 \%)$, montagem $(2 \%)$, outras aplicações diversas $(5 \%)$. Dentre as aplicações diversas, pode-se destacar a solda laser, a solda plasma, moldes plásticos, usinagem, pintura e revestimento, fundição e inspeção e testes. No mundo, e considerando-se todas as indústrias, o
Japão está em primeiro lugar em número de robôs instalados. Na indústria automobilística do Japão, a densidade de robôs instalados em relação à mão de obra é de 1 robô para cada 10 trabalhadores. Dos 999.100 robôs instalados no mundo até 2007, o Japão possuia $40 \%$, seguido pela Alemanha com $14 \%$. O Brasil tem cerca de $0,3 \%$ dos robôs instalados ao redor do mundo. A introdução do sistema de manufatura flexível e a robotização trazem necessidades de especialização de mão de obra, que deve ser orientada para ambientes computadorizados, aos quais, os trabalhadores mais novos, com idade inferior a 40 anos, normalmente adaptam-se com maior facilidade (CHONG; SALVENDY, 1999). A utilização de robôs pode prover flexibilidade na produção e rápidas respostas às necessidades de adequação da produção ao mercado. Robôs são reprogramáveis e, portanto, podem ser reutilizados, trazem redução de mão de obra e benefícios em custos, incluindo aumento da produção, redução de custos operacionais, aumento na qualidade do produto, eliminação de perigos para a segurança e saúde, alta precisão, operação em turnos sem paradas e redução do espaço fabril no chão de fábrica (MILLS et al., 1999).

Outro apecto importante destacado por Mills et al. (1999) é a viabilidade técnica da robotização. Uma produção robotizada deve prever se seus produtos são projetados de modo que possam ser manipulados por robôs, se os tempos de ciclo das células de produção atendem ao especificado e se há segurança na operação. Outro aspecto importante é a cultura organizacional da empresa na utilização de robôs. A implementação de robôs deve envolver todas as áreas da empresa como engenharia de manufatura, manutenção, engenharia de produtos e finanças. De acordo com Soska (1999), a estratégia para implantação de projetos de robotização deve conter quatro elementos: mudança de paradigmas, comunicação interna na empresa, esforços coordenados dos setores e parcerias com fornecedores.

Uma parte relevante do processo estratégico é a medição e o controle dos resultados gerados pela sua implementação, segundo Sellitto e Walter (2006), e no caso da estratégia de manufatura existem dois denominadores para medição de rendimento e controle: o primeiro é baseado no tempo e o segundo denominador é baseado nos custos (HILL, 2000). Além disso, o tamanho da empresa e a relação da estratégia geral com a de manufatura traz impactos diferenciados na performance financeira da organização (KAZAN; ÖZER; ÇETIN, 2006).

Um dos mais importantes critérios na elaboração da estratégia de manufatura é a decisão de investimentos e o processo de decisão pode ser dividido em quatro elementos principais: estruturação, coleta de informações, conclusões e aprendizado (HILL, 2000). A estruturação significa definir o que deve ser decidido e determinar os critérios de preferência 
entre as opções. A coleta de informações é a busca de fatos e seu reconhecimento para a tomada de decisão. Nas conclusões, estruturam-se as informações e adicionam-se aspectos qualitativos que definem a decisão. $\mathrm{O}$ aprendizado se dá com o armazenamento e realimentação das informações para futuras decisões (RUSSO; SCHOEMAKER, 1993). Segundo Hill (2000), as organizações possuem recursos limitados e, por isso, tais decisões são tomadas com cautela e baseadas em profunda análise. $\mathrm{O}$ argumento de que o investimento deve trazer um rápido retorno (payback) é atraente sob a ótica financeira, entretanto, considerado de forma isolada pode levar a decisões equivocadas quando o objetivo é melhorar a competitividade estratégica.

Especificamente em relação aos investimentos em ativos na manufatura, Slack e Lewis (2008) afirmam que a principal medida de desempenho é o retorno financeiro sob a forma de retorno sobre investimento, ou ROI (return on investiment). Mas o investimento em manufatura é estratégico à medida que afeta a competitividade da empresa e influencia a operação em termos de qualidade, velocidade, confiabilidade e flexibilidade. Se for considerado somente o ROI, os investimentos podem ser inviáveis e, por isso, precisam ser considerados parâmetros de natureza estratégica também (SLACK; LEWIS, 2008). Em relação aos custos, um critério mais abrangente de avaliação crescentemente utilizado é o Custo Total de Propriedade (TCO - Total Cost Ownership), ou seja, os custos desde a compra do equipamento até o seu descarte (BIERMA; WATERSTRAAT, 2004). Por meio do TCO projeta-se, além do custo direto de aquisição do equipamento, os custos indiretos, ou seja, os custos futuros que o equipamento demandará em seu ciclo de vida, como peças de reposição, custos de manutenção, treinamentos especiais e consumíveis (WILD; HERGES, 2000).

Para Mills et al. (1999), e Lander e Bayou (1992), investimentos em robotização e manufatura flexível têm potencial para redução de custos, aumento da flexibilidade e qualidade, e aumento da produtividade, mas justificar tais investimentos se torna difícil caso sejam considerados apenas aspectos econômicos e financeiros, e, neste sentido, a decisão em robotização deve ser iniciada com uma análise não econômica. Os motivos para a robotização não relacionam-se apenas à substituição de mão de obra por robôs e as análises que suportam decisões de investimentos em robotização devem considerar a comparação entre o custo de capital e os custos de operação da instalação de robôs, levando em conta também fluxo de caixa projetado. $\mathrm{Na}$ fase de análise de custo, deve-se determinar os custos e benefícios na instalação de robôs industriais, seu custo de investimento, vendas projetadas, lucro e ganhos operacionais. Nessa análise deve se incluir não só o custo do robô industrial como também o custo de ferramental acoplado, dispositivos de transferência para outras células de produção, equipamentos de segurança para os operadores, custos de manutenção e treinamento do pessoal. Todos os ganhos operacionais também devem ser incluídos tais como ganhos de mão de obra, consumíveis, tempo efetivo de operação, redução de afastamento de pessoal devido a problemas de ergonomia, como LER - Lesão por Esforço Repetitivo -, e redução de sucata (MILLS et al., 1999).

A compra de bens de capital de alta tecnologia se diferencia da compra de itens gerais de consumo. Bens de capital de alta tecnologia possuem um longo ciclo de vida de operação que demanda peças de reposição bem como serviços. Neste sentido, a decisão de investimento em robotização também deve levar em conta aspectos como a parceria com o fornecedor de robôs. Peças de reposição são itens de alto valor agregado e deve-se considerar as alternativas de fazer investimento direto ou consignação com o fornecedor de robôs. Parceria com fornecedor significa também evitar a inclusão de diferentes marcas de robôs em uma mesma planta pois diferentes marcas necessitam de diferentes treinamentos para os operadores, diferentes peças de reposição e eventual dificuldade de comunicação entre equipamentos (SOSKA, 1999).

\section{Metodologia da pesquisa na indústria de autopeças}

No sentido de identificar os fatores determinantes no processo de decisão de investimentos em robotização na indústria brasileira de autopeças, foi desenvolvida uma pesquisa de campo em três etapas junto às empresas de autopeças brasileiras no período de 09/07/2008 a 20/08/2008.

Na primeira etapa da pesquisa, foram realizadas entrevistas com os diretores gerais de quatro fabricantes de robôs sediados no Brasil, visando obter informações sobre o perfil das pessoas que decidem ou influenciam a decisão sobre robotização nas empresas de autopeças, que podem ser diretores, gerentes ou analistas, e que foram os sujeitos da pesquisa.

$\mathrm{Na}$ segunda etapa da pesquisa, foram entrevistados seis especialistas do setor de autopeças no sentido de obter informações sobre a tomada de decisão em robotização que subsidiassem o posterior desenvolvimento do formulário de pesquisa. Durante as entrevistas abertas com especialistas, foram questionados quais são os pontos mais importantes a serem considerados na tomada de decisão de investimentos em robotização (Quadro 1).

Com base nas duas primeiras etapas qualitativas, e na bibliografia explorada, foi construído um instrumento de pesquisa, delineado de forma qualitativa, com 27 variáveis dispostas por meio de 
Quadro 1. Pontos importantes para a tomada de decisão em robotização.

\begin{tabular}{|c|c|c|c|c|c|c|}
\hline & \multicolumn{6}{|c|}{ Especialistas } \\
\hline & 1 & 2 & 3 & 4 & 5 & 6 \\
\hline Tempo de experiência & 14 anos & 7 anos & 12 anos & 11 anos & 7 anos & 6 anos \\
\hline Custo & $x$ & $x$ & $x$ & $x$ & $x$ & $x$ \\
\hline Produtividade & $x$ & $x$ & - & $x$ & - & - \\
\hline Qualidade & $x$ & $x$ & $x$ & $x$ & $x$ & $x$ \\
\hline Flexibilidade & $x$ & - & $x$ & $x$ & - & $x$ \\
\hline Tecnologia & - & $x$ & - & - & - & $x$ \\
\hline Estratégia & - & $x$ & - & - & - & $x$ \\
\hline Desenvolvimento de produto & - & $x$ & - & - & - & - \\
\hline Confiabilidade & $x$ & - & - & - & - & - \\
\hline Ergonomia & $x$ & - & - & - & $x$ & - \\
\hline
\end{tabular}

Fonte: Elaborado pelos autores com base em pesquisa de campo.

assertivas e uma escala Likert de 5 níveis variando entre Discordo totalmente (1) até Concordo totalmente (5), conforme o Quadro 2.

Finalmente, na terceira etapa, foi realizada uma pesquisa exploratória quantitativa, caracterizada como levantamento, junto às empresas associadas ao Sindipeças, que formam uma população de 488 empresas, e são responsáveis por $95 \%$ da produção local destinada às montadoras, ao segmento de reposição e ao mercado externo (SINDICATO NACIONAL DA INDÚSTRIA DE COMPONENTES PARA VEÍCULOS AUTOMOTORES, 2008). Foram enviados 329 instrumentos de pesquisa que resultaram em amostra de 119 formulários respondidos e tabulados para análise, ou $24,4 \%$ da população. A amostra abrange todos os segmentos da indústria: plásticos, borrachas, conjuntos estampados, conjuntos soldados, usinagem seriada, forjados e fundidos.

\section{Análise dos resultados}

A análise dos dados extraídos dos 119 formulários deu-se por meio de análise fatorial exploratória, e os respondentes (98,3\% do sexo masculino) atuavam diretamente na área de manufatura em posições que os qualificava para responder às perguntas formuladas: diretores $(7 \%)$, gerentes $(35 \%)$, engenheiros de manufatura (42\%), compradores (9\%) e manutenção (7\%). Embora não fosse uma pré condição para participar da pesquisa, que foi orientada também para empresas que pretendiam robotizar, o nível de robotização das empresas pesquisadas é relativamente alto, dado que apenas $25 \%$ não tinham robôs; $35 \%$, até dez robôs; e $40 \%$ tinham mais de dez robôs. Inicialmente foi aplicado o teste de aderência à distribuição normal de Kolmogorov-Smirnov que, segundo Siegel (1979), aplica-se a amostras superiores a 50 unidades. O resultado do teste de KolmogorovSmirnov obteve uma significância inferior a $\alpha=0,05$
(Asymp. Sig < 0,05), configurando uma amostra que não apresenta uma distribuição normal, mas, segundo Hair et al. (2005), para análise fatorial exploratória não há necessidade de uma normalidade na amostra. Dada a não normalidade da distribuição, deve-se aplicar análises não paramétricas à amostra.

Os dados de uma matriz devem possuir correlações suficientes para a aplicação de análise fatorial. Duas maneiras para determinar a adequação de uma análise fatorial é analisar a correlação da matriz inteira ou as correlações parciais de cada variável (HAIR et al., 2005). Para o teste de correlação para a matriz inteira, aplicou-se o teste Bartlett de esfericidade e medida de adequação da amostra (MSA) de Kaiser-MeyerOlkin (KMO). A medida de adequação da amostra KMO apresentou um valor de 0,631 . De acordo com Hair et al. (2005), valores entre 0,6 e 0,7 apresentam um correlação aceitável, porém, com suficiente intercorrelação entre as variáveis. Valores abaixo de 0,5 são considerados inaceitáveis; de 0,5 a 0,6, ruins; acima de 0,7 , as intercorrelações tornam-se medianas; e acima de 0,8, admiráveis.

Após o teste de correlação, observa-se na matriz de correlação, fornecida pelo SPSS 13.0 para Windows, os valores individuais das variáveis para identificar quais variáveis possuem valores abaixo de 0,5 , consideradas inaceitáveis para a aplicação de análise fatorial. Esses valores devem ser observados nas diagonais da matriz de correlação Anti-imagem. As variáveis $\mathrm{v} 1$, v5 e v11 possuiam valores inferiores a 0,5 na diagonal da matriz. Devido a essas variáveis, nessa amostra, obterem baixa intercorrelação com as outras variáveis, foram eliminadas da análise fatorial. Aplicaram-se novamente testes de Bartlett de esfericidade e medida de adequação da amostra (MSA) de Kaiser-Meyer-Olkin (KMO), obtendo os resultados positivos e indicando que os dados estão preparados para a análise fatorial. 
Quadro 2. Instrumento de pesquisa e suas variáveis.

\begin{tabular}{|c|c|}
\hline Variável & Assertiva \\
\hline $\mathrm{v} 1$ & A robotização industrial deve ser feita apenas para produtos desenhados para processos robotizados. \\
\hline $\mathrm{v} 2$ & $\begin{array}{l}\text { O investimento em robotização industrial deve levar em conta sua flexibilidade de aplicação em } \\
\text { diversos tipos de processos antes de uma análise financeira do investimento. }\end{array}$ \\
\hline v3 & $\begin{array}{l}\text { A busca de competitividade da empresa não passa sempre pelo setor produtivo, independente da } \\
\text { estratégia da empresa. }\end{array}$ \\
\hline $\mathrm{v} 4$ & $\begin{array}{l}\text { A análise financeira do robô industrial e do sistema (célula) ao qual o robô está inserido deve estar } \\
\text { associada ao ciclo de vida do produto. }\end{array}$ \\
\hline v5 & $\begin{array}{l}\text { Para trabalhos que ofereçam perigo para o ser humano, devem ser aplicados robôs independentemente } \\
\text { do retorno financeiro do investimento. }\end{array}$ \\
\hline v6 & $\begin{array}{l}\text { As tecnologias de produção das empresas de autopeças devem estar alinhadas com as tecnologias de } \\
\text { produção das montadoras de veículos. }\end{array}$ \\
\hline v7 & $\begin{array}{l}\text { Investir em robôs industriais é importante, pois se trata de tecnologia de última geração, independente } \\
\text { dos custos. }\end{array}$ \\
\hline v8 & $\begin{array}{l}\text { As decisões de investimento em tecnologia de produção devem ser feitas exclusivamente por } \\
\text { engenheiros e especialistas de processo. }\end{array}$ \\
\hline v9 & A estratégia de manufatura não deve estar sempre subordinada à estratégia principal da empresa. \\
\hline v10 & $\begin{array}{l}\text { O aumento de qualidade dos produtos produzidos por robôs é suficiente para justificar seu } \\
\text { investimento, independente do retorno financeiro e pay-back. }\end{array}$ \\
\hline v11 & $\begin{array}{l}\text { A grande dificuldade das análises de investimento em robotização industrial não é o custo de } \\
\text { aquisição de um robô, mas o custo do sistema em que o robô está inserido. }\end{array}$ \\
\hline v12 & $\begin{array}{l}\text { Na composição da estratégia de investimento em equipamentos, tecnologia é mais importante que o } \\
\text { retorno de investimento. }\end{array}$ \\
\hline v13 & $\begin{array}{l}\text { Deve-se investir em robotização industrial somente se houver retorno financeiro e pay-back, de acordo } \\
\text { com a política da empresa. }\end{array}$ \\
\hline v14 & $\begin{array}{l}\text { Mesmo sem retorno de investimento, utilizar robôs é importante devido à qualidade que estes trazem } \\
\text { para a produção. }\end{array}$ \\
\hline v15 & $\begin{array}{l}\text { O uso de uma análise financeira como retorno sobre investimento não se aplica a robôs industriais, } \\
\text { pois esses são bens duráveis flexíveis utilizados em outros projetos. }\end{array}$ \\
\hline v16 & $\begin{array}{l}\text { Independente do custo de investimento em tecnologias na produção, tais investimentos devem ser } \\
\text { feitos, se for solicitação do cliente final (por ex. montadora). }\end{array}$ \\
\hline v17 & $\begin{array}{l}\text { No cálculo de retorno de investimento em robôs industriais não se deve levar em conta a redução de } \\
\text { mão de obra que este irá trazer. }\end{array}$ \\
\hline v18 & $\begin{array}{l}\text { Investir em robôs industriais é importante, independente do retorno financeiro, porque mostra aos } \\
\text { clientes um parque industrial moderno. }\end{array}$ \\
\hline v19 & $\begin{array}{l}\text { O robô deve estar associado ao ciclo de vida do produto e, por isso, seu custo de aquisição deve ser o } \\
\text { menor possível para viabilizar o investimento. }\end{array}$ \\
\hline $\mathrm{v} 20$ & Nem sempre se deve analisar índices financeiros antes de se definir o tipo de tecnologia de produção. \\
\hline v21 & A robotização industrial é eficaz porque basicamente reduz mão de obra. \\
\hline $\mathrm{v} 22$ & Não importa a estratégia de manufatura, novas tecnologias de produção devem estar em primeiro plano. \\
\hline v23 & $\begin{array}{l}\text { O robô industrial deve ser considerado como um bem durável não só para um projeto, mas para } \\
\text { projetos futuros, como um investimento a longo prazo. }\end{array}$ \\
\hline $\mathrm{v} 24$ & $\begin{array}{l}\text { Investimento em robotização deve contemplar apenas o custo de aquisição. Não é necessário análise } \\
\text { de investimento em robôs levando em conta desde a compra do equipamento até o seu descarte e } \\
\text { peças de reposição. }\end{array}$ \\
\hline v25 & $\begin{array}{l}\text { Analisar um investimento em robotização industrial deve ser feito a longo prazo, considerando a } \\
\text { flexibilidade de aplicação de um robô. }\end{array}$ \\
\hline v26 & $\begin{array}{l}\text { Os investimentos em robôs industriais não devem estar associados ao ciclo de vida do produto que } \\
\text { este irá produzir. }\end{array}$ \\
\hline v27 & $\begin{array}{l}\text { O aumento de produtividade em robotização justifica seus investimentos, independente do pay-back } \\
\text { exigido pela empresa. }\end{array}$ \\
\hline
\end{tabular}

Fonte: Elaborado pelos autores. 
A análise de componentes principais e a análise de fatores comuns são modelos para obtenção de soluções fatoriais. A análise de componentes principais considera a variância total e determina fatores que contêm pequenas proporções de variância única, e esses fatores, com as respectivas cargas das variáveis, identificarão a estrutura latente (HAIR et al., 2005). A determinação dos fatores da pesquisa será dada pela análise de componentes principais. A extração de fatores utilizando o autovalor torna-se confiável em um conjunto de variáveis entre 20 e 50 unidades (27 no instrumento de pesquisa). Esse critério é chamado de critério da raiz latente. Cada fator individual deve explicar a variância de pelo menos uma variável, ou seja, cada variável contribui com valor 1 do autovalor total e os autovalores inferiores a 1 são descartados (HAIR et al., 2005).

Ainda segundo Hair et al. (2005), outro critério para extração de fatores seria o critério da percentagem de variância. Em ciências sociais, $60 \%$ da variância total pode ser considerada como satisfatória, devido às informações serem menos precisas se comparadas com ciências naturais.A ordem de importância dos fatores foi caracterizada conforme a percentagem de variância de cada um. A matriz não rotacionada contém os 8 fatores extraídos e as cargas fatoriais para cada variável em cada fator. Para a obtenção de um padrão fatorial mais significativo, deve-se rotacionar a matriz fatorial buscando-se uma melhor redistribuição da variância entre os fatores.

$\mathrm{Na}$ análise, foi feita uma rotação ortogonal, ou seja, 90 graus entre os fatores. O método de rotação utilizado foi o Varimax, que, segundo Hair et al. (2005), maximiza a soma de variâncias de cargas exigidas da matriz fatorial. Para as cargas fatoriais, Hair et al. (2005) afirmam que, no caso de amostras maiores que 100 , as cargas maiores que $+/-0,30$ atingem o nível mínimo, acima de +/- 0,40 são consideradas importantes, e acima de $+/-$ 0,50 com significância prática. Para a análise, devemos associar cada variável a apenas um fator, com isso, para cada variável será assumido o fator em que ela possui maior carga fatorial. Na Tabela 1 pode-se observar o resultado da matriz rotacionada, mantendo-se a maior carga fatorial de cada variável.

Tabela 1. Matriz de componentes rotacionada (variáveis com maior carga).

\begin{tabular}{|c|c|c|c|c|c|c|c|c|c|}
\hline \multicolumn{9}{|c|}{ Componentes } & \multirow{2}{*}{$\begin{array}{c}\text { Comunalidades } \\
\text { Extração }\end{array}$} \\
\hline & 1 & 2 & 3 & 4 & 5 & 6 & 7 & 8 & \\
\hline $\mathrm{v} 2$ & - & - & - & - & - & - & 0,5084 & - & 0,4945 \\
\hline v3 & - & - & - & - & - & - & 0,7391 & - & 0,6511 \\
\hline v4 & - & - & - & 0,7064 & - & - & - & - & 0,5865 \\
\hline v6 & - & - & 0,6196 & - & - & - & - & - & 0,5986 \\
\hline v7 & 0,5135 & - & - & - & - & - & - & - & 0,5883 \\
\hline v8 & - & - & - & - & - & - & - & $-0,6794$ & 0,7002 \\
\hline v9 & - & 0,4420 & - & - & - & - & - & - & 0,4645 \\
\hline v10 & 0,5037 & - & - & - & - & - & - & - & 0,6893 \\
\hline v12 & 0,5174 & - & - & - & - & - & - & - & 0,6262 \\
\hline v13 & - & - & - & - & - & $-0,8059$ & - & - & 0,6759 \\
\hline v14 & 0,5473 & - & - & - & - & - & - & - & 0,5048 \\
\hline $\mathrm{v} 15$ & - & 0,6880 & - & - & - & - & - & - & 0,5894 \\
\hline v16 & - & 0,7561 & - & - & - & - & - & - & 0,7244 \\
\hline v17 & - & & - & - & - & 0,5078 & - & - & 0,5571 \\
\hline v18 & - & 0,6151 & - & - & - & - & - & - & 0,5908 \\
\hline v19 & - & - & - & 0,8078 & - & - & - & - & 0,7284 \\
\hline v20 & - & - & - & - & - & - & - & 0,6707 & 0,5472 \\
\hline v21 & 0,6487 & - & - & - & - & - & - & - & 0,5760 \\
\hline v22 & 0,7335 & - & - & - & - & - & - & - & 0,6393 \\
\hline v23 & - & - & & - & 0,7899 & - & - & - & 0,6724 \\
\hline v24 & - & - & 0,7114 & - & & - & - & - & 0,5589 \\
\hline v25 & - & - & - & - & 0,8217 & - & - & - & 0,7255 \\
\hline v26 & - & - & - & $-0,6031$ & - & - & - & - & 0,6940 \\
\hline v27 & - & - & 0,6186 & - & - & - & - & - & 0,5894 \\
\hline
\end{tabular}

Fonte: Pesquisa de campo e SPSS. 
Na Tabela 2, podemos observar os fatores e suas respectivas variáveis.

Antes da análise dos fatores, faz-se necessária uma avaliação do grau de consistência entre as medidas das variáveis, ou seja, a confiabilidade do instrumento de pesquisa. $\mathrm{O}$ coeficiente mais utilizado segundo Hair et al. (2005) é o alfa de Cronbach. O alfa de Cronbach é um índice normalizado que varia de 0 a 1, sendo aceitáveis valores acima de 0,6 para pesquisas exploratórias. Aplicado o coeficiente alfa de Cronbach de confiabilidade e feita a inversão dos escores das variáveis v8, v13, v26, a fim de evitar uma neutralização de cargas positivas e negativas no teste, observou-se que os fatores 3, 6, 7 e 8 foram considerados abaixo do nível aceitável. Por se tratarem de fatores com variáveis relevantes à pesquisa, apenas os fatores 7 e 8 serão descartados da análise final por estarem muito abaixo do limite inferior de 0,6.

No sentido de analisar os fatores e as variáveis individualmente, foi realizada uma análise de tendência entre discordância e concordância com base no agrupamento das frequências das respostas em três níveis: discordância, indiferença e concordância, com base na Tabela 3. Ao analisar-se o fator 1, observou-se nele a maior correlação entre as variáveis. O robô industrial possui um alto valor agregado, ou seja, um alto valor no custo de aquisição. De acordo com Slack e Lewis (2008), se considerarmos apenas o retorno de investimento (ROI) como critério de análise para a tomada de decisão em investimentos de robotização, estes tornam-se proibitivos, por isso, deve-se avaliar o investimento conforme sua viabilidade, aceitabilidade e vulnerabilidade. O resultado da pesquisa, entretanto, mostrou que, mesmo com a associação qualidade e tecnologia, os custos aparecem como principal item do trinômio. A pesquisa identificou que, diferentemente do que Slack e Lewis (2008) diz, os investimentos em manufatura não se fundamentam unicamente em tecnologia, mas essencialmente, nas análises financeiras e, conforme a variável 21 , nos recursos humanos necessários a uma robotização. De acordo com Mills et al. (1999), robotizar não significa apenas substituir mão de obra por robôs, e isso foi

Tabela 2. Fatores $\times$ variáveis.

\begin{tabular}{cc}
\hline Fator (construto) & Variável \\
\hline Fator 1 & $\mathrm{v} 7 ; \mathrm{v} 10 ; \mathrm{v} 12 ; \mathrm{v} 14 ; \mathrm{v} 21 ; \mathrm{v} 22$ \\
Fator 2 & $\mathrm{v} 9 ; \mathrm{v} 15 ; \mathrm{v} 16 ; \mathrm{v} 18$ \\
Fator 3 & $\mathrm{v} 6 ; \mathrm{v} 24 ; \mathrm{v} 27$ \\
Fator 4 & $\mathrm{v} 4 ; \mathrm{v} 19 ;-\mathrm{v} 26$ \\
Fator 5 & $\mathrm{v} 23 ; \mathrm{v} 25$ \\
Fator 6 & $-\mathrm{v} 13 ; \mathrm{v} 17$ \\
Fator 7 & $\mathrm{v} 2 ; \mathrm{v} 3$ \\
Fator 8 & $-\mathrm{v} 8 ; \mathrm{v} 20$ \\
\hline
\end{tabular}

Fonte: Pesquisa de campo e SPSS. confirmado na pesquisa, porém eles também afirmam que investimentos em robotização e manufatura flexível têm potencial de redução de custos, mas tais investimentos tornam-se difíceis se considerados apenas por análises econômicas.

No fator 2, de acordo com a pesquisa, a estratégia de manufatura deve estar subordinada a uma estratégia de negócios, confirmando Skinner (1969), Wheelwright (1984) e Cagliano, Caniato e Spina (2006). Assim como observado no fator 1 , os investimentos em robotização industrial não são baseados somente em tecnologia e manufatura, mas sim, atrelados à estratégia financeira, também de forma divergente de Slack e Lewis (2008).

Santos e Pinhão (2000) afirmam que qualidade, máquinas especiais de produção e sistemas de logística são pré-requisitos para fornecimento de sistemas modulares às montadoras. Os robôs industriais são máquinas especiais para a produção e podemos entender que a forma como a assertiva foi colocada, evidenciando a montadora como cliente, mostra que a estratégia de manufatura e a estratégia financeira da empresa, cedem espaço uma a outra, conforme a natureza da relação de fornecimento entre a autopeça e a montadora. Temos no fator 3 a corroboração de que as tecnologias de produção das empresas de autopeças devem estar alinhadas com as tecnologias das montadoras. A produtividade das linhas das autopeças devem seguir os mesmos preceitos das linhas das montadoras, por meio de tecnologia e qualidade, porém, somente se houver paralelos retornos financeiros, ou seja, o alinhamento tecnológico deve respeitar os critérios de análise financeira da estratégia de negócio da empresa de autopeças.

Associar investimentos ao ciclo de vida do produto reduz riscos segundo Hill (2000) e Mills et al. (1999), e o fator 4 nos mostrou que os respondentes das autopeças associam a robotização industrial e seus investimentos ao ciclo dos produtos que estes irão produzir, reduzindo riscos. Podemos observar que não só o robô industrial mas seus componentes (célula e ferramenta) também devem estar associados ao ciclo do produto em consonância com Soska (1999), que afirma que o investimento em robotização não se resume à compra apenas do robô industrial, mas sim a todo um sistema ao qual ele está inserido.

Em uma análise de investimento em robô industrial paralela ao ciclo de produto, temos no fator $5 \mathrm{o}$ investimento em robotização como um investimento a longo prazo. Esse investimento deve estar atrelado às metas gerenciais e analisado a longo prazo, sob risco da aquisição tornar-se inviável. Na análise de tendência do fator 5, observou-se que mais de $60 \%$ dos respondentes concordam que os investimentos em robotização devem ser feitos a longo prazo. Esse fato acaba por contradizer o fator 4 no qual temos os investimentos em robotização atrelados ao ciclo de 
Tabela 3. Análise de tendência por variável.

\begin{tabular}{|c|c|c|c|c|c|}
\hline Fator & Variável & Assertiva & $\begin{array}{l}\text { Discorância } \\
(\%)\end{array}$ & $\begin{array}{c}\text { Indiferença } \\
(\%)\end{array}$ & $\begin{array}{c}\text { Concordância } \\
(\%)\end{array}$ \\
\hline \multirow[t]{6}{*}{1} & v7 & $\begin{array}{l}\text { Investir em robôs industriais é importante, pois trata-se de } \\
\text { tecnologia de ponta, independente dos custos. }\end{array}$ & 66,4 & 29,4 & 4,2 \\
\hline & v10 & $\begin{array}{l}\text { O aumento de qualidade dos produtos produzidos por robôs } \\
\text { é suficiente para justificar seu investimento, independente } \\
\text { do retorno financeiro e pay-back. }\end{array}$ & 65,5 & 26,9 & 7,6 \\
\hline & v12 & $\begin{array}{l}\text { Na composição da estratégia de investimento em } \\
\text { equipamentos, tecnologia é mais importante que o retorno } \\
\text { de investimento. }\end{array}$ & 69,7 & 23,5 & 6,7 \\
\hline & v14 & $\begin{array}{l}\text { Mesmo sem retorno de investimento, utilizar robôs é } \\
\text { importante devido à qualidade que estes trazem para a } \\
\text { produção. }\end{array}$ & 52,1 & 33,6 & 14,3 \\
\hline & v21 & $\begin{array}{l}\text { A robotização é eficaz porque basicamente reduz mão de } \\
\text { obra. }\end{array}$ & 53,8 & 30,3 & 16,0 \\
\hline & v22 & $\begin{array}{l}\text { Não importa a estratégia de manufatura, novas tecnologias } \\
\text { de produção devem estar em primeiro plano. }\end{array}$ & 51,3 & 29,4 & 19,3 \\
\hline \multirow[t]{4}{*}{2} & v9 & $\begin{array}{l}\text { A estratégia de manufatura não deve estar sempre } \\
\text { subordinada à estratégia principal da empresa. }\end{array}$ & 63,9 & 15,1 & 21,0 \\
\hline & v15 & $\begin{array}{l}\text { O uso de uma análise financeira como retorno sobre } \\
\text { investimento não se aplica a robôs industriais, pois esses são } \\
\text { bens duráveis flexíveis utilizados em outros projetos. }\end{array}$ & 68,9 & 18,5 & 12,6 \\
\hline & v16 & $\begin{array}{l}\text { Independente do custo de investimento em tecnologias } \\
\text { na produção, tais investimentos devem ser feitos se for } \\
\text { solicitação do cliente final (por ex. montadora). }\end{array}$ & 49,6 & 16,0 & 34,5 \\
\hline & v18 & $\begin{array}{l}\text { Investir em robôs industriais é importante, independente do } \\
\text { retorno financeiro, porque mostra aos clientes um parque } \\
\text { industrial moderno. }\end{array}$ & 73,1 & 21,8 & 5,0 \\
\hline \multirow[t]{3}{*}{3} & v6 & $\begin{array}{l}\text { As tecnologias de produção das empresas de autopeças } \\
\text { devem estar alinhadas com as tecnologias de produção das } \\
\text { montadoras. }\end{array}$ & 10,9 & 23,5 & 65,5 \\
\hline & v24 & $\begin{array}{l}\text { Investimento em robotização deve contemplar apenas o } \\
\text { custo de aquisição. Não é necessário análise de investimento } \\
\text { levando em conta desde a compra do equipamento até o seu } \\
\text { descarte. }\end{array}$ & 85,7 & 4,2 & 10,1 \\
\hline & v27 & $\begin{array}{l}\text { O aumento de produtividade em robotização justifica seus } \\
\text { investimentos, independente do pay-back exigido pela } \\
\text { empresa. }\end{array}$ & 58,8 & 21,0 & 20,2 \\
\hline \multirow[t]{3}{*}{4} & v4 & $\begin{array}{l}\text { A análise financeira do robô industrial e de seu sistema deve } \\
\text { estar associada ao ciclo de vida do produto. }\end{array}$ & 16,8 & 18,5 & 64,7 \\
\hline & v19 & $\begin{array}{l}\text { O robô deve estar associado ao ciclo de vida do produto e } \\
\text { por isso seu custo de aquisição deve ser o menor possível } \\
\text { para viabilizar o investimento. }\end{array}$ & 31,1 & 26,1 & 42,9 \\
\hline & $-v 26$ & $\begin{array}{l}\text { Os investimentos em robôs industriais não devem estar } \\
\text { associados ao ciclo de vida do produto que este irá produzir. }\end{array}$ & 31,1 & 21,0 & 47,9 \\
\hline \multirow[t]{2}{*}{5} & v23 & $\begin{array}{l}\text { O robô industrial deve ser considerado como um bem } \\
\text { durável não só para um projeto, mas para projetos futuros, } \\
\text { como um investimento de longo prazo. }\end{array}$ & 10,1 & 21,8 & 68,1 \\
\hline & v25 & $\begin{array}{l}\text { Analisar um investimento em robotização industrial deve } \\
\text { ser feito a longo prazo, considerando a flexibilidade de } \\
\text { aplicação do robô. }\end{array}$ & 10,1 & 21,0 & 68,9 \\
\hline \multirow[t]{2}{*}{6} & $-\mathrm{v} 13$ & $\begin{array}{l}\text { Deve-se investir em robotização industrial somente se } \\
\text { houver retorno financeiro e pay-back, de acordo com a } \\
\text { política da empresa. }\end{array}$ & 52,1 & 27,7 & 20,2 \\
\hline & v17 & $\begin{array}{l}\text { No cálculo de retorno de investimento em robôs industriais } \\
\text { não se deve levar em conta a redução de mão de obra que } \\
\text { trará. }\end{array}$ & 79,0 & 10,9 & 10,1 \\
\hline
\end{tabular}

Fonte: Elaborada pelos autores com base em pesquisa de campo e SPSS. 
Quadro 3. Fatores.

\begin{tabular}{|cl|}
\hline $\begin{array}{c}\text { Fator } \\
\text { construto) }\end{array}$ & \multicolumn{1}{c|}{ Descrição } \\
\hline Fator 1 & Tecnologia, qualidade e custos \\
Fator 2 & Estratégia funcional e investimentos \\
Fator 3 & Produtividade e cliente \\
Fator 4 & Robotização associada ao produto \\
Fator 5 & Investimento a longo prazo \\
Fator 6 & Robotizar independente dos custos \\
\hline
\end{tabular}

Fonte: Elaborado pelo autores.

vida do produto, e o tempo de vida dos veículos está cada vez menor. Neste sentido, Mills et al. (1999) afirmam que produtos projetados para fabricação utilizando robôs industriais trazem flexibilidade na produção. A associação dos investimentos em robotização a longo prazo com produtos com ciclo de vida cada vez menores deve-se à intermodularidade dos vários produtos e modelos das montadoras, que se reflete nos modelos das autopeças.

Para Mills et al. (1999), aspectos intangíveis devem ser considerados na decisão em robotização e a decisão em robotização deve ser iniciada com uma análise não econômica. No fator 6 , a maioria dos respondentes (52\%) discordou de que se deve investir em robotização industrial somente se houver retorno financeiro e pay-back, de acordo com a política da empresa, contrapondo o resultado das variáveis do fator 1 , no qual o retorno de investimento é mais importante que resultados como qualidade. Essa assertiva não possui um trade-off entre custos e outras características, o que pode ter sugestionado os respondentes a discordarem. Slack e Lewis (2008) afirmam que a seleção de processos tecnológicos deve levar em conta, além de outros itens, o grau de automação, ou seja, o equilíbrio ente máquinas e mão de obra direta, em um sistema. Mesmo com economia em redução de mão de obra, a robotização deve levar em conta a redução da variabilidade em um sistema de manufatura. Com isso, ao analisarem-se as respostas no fator 6 , constata-se que a pesquisa coincide com as afirmações de Mills et al. (1999) e Slack e Lewis (2008).

Com base na análise efetuada, nomearam-se os fatores de acordo com suas características e correlações, conforme o Quadro 3.

\section{Considerações finais}

As montadoras de veículos, condicionadas por forte concorrência global que impõe contínua inovação e melhoria de qualidade, associadas à redução de custos, criam novas demandas para seus principais fornecedores, que são as empresas de autopeças. Algumas destas demandas relacionam-se diretamente a investimentos em bens de capital, que têm papel central nas estratrégias de manufatura e impactam a competitividade das empresas. Entre os investimentos em bens de capital destaca-se a robotização, que teve início nas montadoras, é crescentemente adotada pela empresas de autopeças e dissemina-se por várias outras indústrias no Brasil.

As decisões de investimento acerca da robotização industrial, embora impactando mais diretamente a área de manufatura, são de natureza estratégica e interfuncional. Os investimentos em robotização são relativamente altos e se dão, além do nível dos ativos tangíveis, em uma série de fatores intangíveis como o realinhamento organizacional, processos e formação de recursos humanos. Outros aspectos intangíveis inerentes à robotização, como redução de trabalhos tediosos e repetitivos da mão de obra, ergonomia e redução de afastamentos por LER (Lesão por Esforço Repetitivo) também revestem as decisões de investimento.

O resultado da pesquisa realizada junto às empresas de autopeças do Brasil identificou que o custo e o retorno a longo prazo relacionados à robotização industrial são os fatores mais importantes em uma tomada de decisão de investimentos desse tipo. Outros fatores como tecnologia, qualidade e produtividade possuem uma importância secundária se não estiverem alinhados com a estratégia financeira do negócio. Em relação especificamente à robotização desta indústria identificou-se, portanto, que a estratégia de manufatura está subordinada à estratégia financeira, a despeito da interfuncionalidade inerente à área. A robotização industrial é entendida como um investimento a longo prazo que deve ser analisado à luz do ciclo de vida de produtos a ele associado e, embora os aspectos intangíveis de uma robotização sejam conhecidos e valorizados no senso comum, de acordo com os resultados da pesquisa realizada, não têm importância significativa na tomada de decisão em robotização na indústria de autopeças brasileira. A estratégia de manufatura de cada empresa determina que tipo de modelo e análise de inventimento está associado à robotização.

Pesquisas complementares poderiam estudar a hipótese de que o elevado peso de aspectos financeiros na decisões em robotização no Brasil estão correlacionados às altas taxas de juros reais que inibem os investimentos em bens de capital em geral. Em países como Japão e Alemanha, com a maior taxa global de robotização da indústria automobilística, e que têm baixas taxas de juros e custo de mão de obra elevados, a importância dos fatores de investimento em robotização deve ser bastante diferente. Haveria, portanto, uma perspectiva de significativa mudança no quadro de robotização industrial do Brasil à medida que o custo de capital ficasse mais equiparado ao dos países desenvolvidos. 


\section{Referências}

BIERMA, T. J.; WATERSTRAAT, F. L. Total Cost of Ownership for metalworking fluids. Illinois: Illinois Waste Management and Research Center, Illinois State University Normal, 2004.

CAGLIANO, R.; CANIATO, F.; SPINA, G. The linkage between supply chain integration and manufacturing improvement programmes. International Journal of Operations \& Production Management, v. 26, n. 3, p. 282-299, 2006.

CHONG, Y.-Y.; SALVENDY, G. Handbook of industrial robotics. $2^{\text {nd }}$ ed. New York: John Wileys \& Sons, 1999.

CLARK, K. Competing through manufacturing and the new manufacturing paradigm: is manufacturing strategy passé? Production and Operations Management, v. 5, n.1, p. 42-68, 1996.

DI SERIO, L. C.; SAMPAIO, M.; PEREIRA, S. F. A evolução dos conceitos de logística: um estudo na cadeia automobilística no Brasil. ANPAD/EnANPAD, 2006.

HAIR, J. F. et al. Análise multivariada de dados. 5. ed. Porto Alegre: Bookman, 2005.

HAYES, R. H.; PISANO, G. P. Manufacturing strategy: at the intersection of two paradigm shifts. Production and Operations Management, v. 5, n.1, p. 25-41, 1996.

HAYES, R. H.; WHEELWRIGHT, S. C. Restoring our competitive edge: competing through manufacturing. New York: John Wiley, 1984.

HILL, T. Manufacturing strategy: text and cases. $3^{\text {rd }}$ ed. New York: McGraw-Hill, 2000.

HITT, M. A.; IRELAND, R.; KOSKISSON, R. Administração estratégica: competitividade e globalização. São Paulo: Pioneira Thomson Learning, 2005.

INTERNATIONAL FEDERATION OF ROBOTICS - IFR. World Robotics 2007. International Federation of Robotics, 2007.

KAYALI, M. M. Real options as a tool for making strategic investment decisions. Journal of American Academy of Business, v. 8, n. 1, p. 282-286, 2006.

KAZAN, H.; ÖZER, G.; ÇETIN, A. T. The effect of manufacturing strategies on financial performance. Measuring Business Excellence, v. 10, n. 1, p. 14-26, 2006.

LANDER, G. H.; BAYOU, M. E. Does ROI apply to robotic factories? Management Accounting, p. 49-53, 1992.

MILLS, J. J. et al. Handbook of industrial robotics. $2^{\text {nd }}$ ed. New York: John Wileys \& Sons, 1999.

MSN money, investing, stocks. Disponível em: <http:// moneycentral.msn.com/investor/ common/findsymbol. asp>. Acesso em: 15 jan. 2009.
PORTER, M. E. Estratégia competitiva: técnicas para ánalise de indústrias e da concorrência. 2. ed. Rio de Janeiro: Elsevier, 2004 .

PORTER, M. E. What is strategy? Harvard Business Review, v. 74, n. 6, p. 61-78, 1996.

PRAJOGO, D. I. et al. Manufacturing strategies and innovation performance in newly industrialized countries. Industrial Management \& Data Systems, v. 107, n. 1, p. 52-68, 2007.

RUSSO, J. E.; SCHOEMAKER, P. J. H. Tomada de decisões - armadilhas. São Paulo: Saraiva, 1993.

SANTOS, A. M. M. M.; PINHÃO, C. M. A. Panorama geral do setor de autopeças. BNDES setorial, n. 11. p. 71-86, 2000.

SCHONBERGER, R. J. World class manufacturing. The lessons of simplicity applied. New York: The Free Press, 1986.

SELLITTO, M. A.; WALTER, C. Avaliação do desempenho de uma manufatura de equipamentos eletrônicos segundo critérios de competição. Produção, v. 16, n.1, p. 34-47, 2006.

SIEGEL, S. Estatística não-paramétrica para ciências do comportamento. São Paulo: McGraw-Hill, 1979.

SINDICATO NACIONAL DA INDÚSTRIA DE COMPONENTES PARA VEÍCULOS AUTOMOTORES - SINDIPEÇAS. Desempenho do setor de Autopeças 2008. SINDIPEÇAS, 2008.

SKINNER, W. Manufacturing-missing link in corporate strategy. Harvard Business Review, v. 47, n. 3, p. $136-145,1969$.

SLACK, N.; LEWIS, M. Operations strategy. 2 ed. Harlow: FT Prentice Hall, 2008.

SOSKA, G. V. Handbook of industrial robotics. $2^{\text {nd }} \mathrm{ed}$. New York: John Wiley \& Sons, 1999.

TREACY, M.; WIERSEMA, F. A disciplina dos líderes de mercado: escolha seus clientes, direcione seu foco, domine seu mercado. Rio de Janeiro: Rocco, 1995.

VOSS, A. C. Alternative paradigms for manufacturing strategy. International Journal of Operations \& Production Management, v. 15, n. 4, p. 5-16, 1995.

WHEELWRIGHT, S. C. Manufacturing strategy: defining the missing link. Strategic Management Journal, v. 5, p. 77-91, 1984.

WHEELWRIGHT, S.; BOWEN, K. The challenge of Manufacturing advantage. Production and Operations Management, v. 5, n. 1, 1996.

WILD, M.; HERGES, S. Total Cost of Ownership (TCO) Ein Überblick. Mainz: Johannes Gutenberg-Universität, 2000.Arbeitspapiere WI, Nr. 1/2000. 